\title{
EFEITO DO HIDROGÊNIO NO AÇO 2,25Cr-1Mo-0,25V ENVELHECIDO EM DIFERENTES CONDIÇÕES*
}

Angela Lorena Cardenas M. ${ }^{1}$ Renata Oliveira da Silva ${ }^{2}$ Carlos Bruno Eckestein ${ }^{3}$ Dilson Silva dos Santos ${ }^{4}$

\section{Resumo}

Este trabalho investigou o efeito do hidrogênio nas propriedades do aço 2,25Cr-1Mo$0,25 \mathrm{~V}$. As amostras foram envelhecidas a $600^{\circ} \mathrm{C}$ por $100 \mathrm{~h}$ e $600 \mathrm{~h}$. Uma parte dos corpos de prova foi deixada somente na condição envelhecida e conduzidas ao ensaio de tração. Outras partes dos corpos de prova foram carregados com hidrogênio, sob tensão elástica e sem tensão aplicada, antes de serem conduzidos ao ensaio de tração. Análises microestrutural e fractografias foram realizadas via microscopia eletrônica de varredura (MEV). Os corpos de prova envelhecidos por $600 \mathrm{~h}$ não apresentaram significante diferença entre as tensões de escoamento e máxima, entre os corpos de prova carreagados com hidrogênio e não carregados (envelhecidos). Os corpos de prova envelhecidos por $100 \mathrm{~h}$ e carregados com hidrogênio, no entanto, apresentaram uma queda nas tensões de escoamento e máxima quando comparadas com os corpos de prova somente envelhecidos.

Palavras-chave: Aço 2,25Cr-1Mo-0,25V; Hidrogênio; Propriedades mecânicas; Envelhecimento

\section{HYDROGEN EFFECT ON THE MECHANICAL PROPERTIES OF 2,25Cr-1Mo- 0,25V STEEL UNDER DIFFERENT AGING CONDITION}

\section{Abstract}

This work investigates the effects of hydrogen on the mechanical properties of $2,25 \mathrm{Cr}-1 \mathrm{Mo}-0,25 \mathrm{~V}$ steel. The samples were aged at $600^{\circ} \mathrm{C}$ for $100 \mathrm{~h}$ and $600 \mathrm{~h}$. For each set, of one of the samples was left uncharged. Hydrogen charging of the other two samples was conducted respectively under stress free and axial elastic stress and conditions. Microstructural analyses and fractographies were performed via scanning electronic microscopy (SEM). Samples aged for $600 \mathrm{~h}$ presented no significant difference concerning yield and ultimate strengths between charged and non-charged samples (aged). Charged samples aged for 100h however, displayed a drop on yield and ultimate strengths when compared to the corresponding noncharged sample.

Keywords: 2,25Cr-1Mo-0,25V steel; hydrogen; mechanical properties; aging.

1 Angela Lorena Cardenas Manosalva, estudante doutorado engenharia metalurgia, Universidade Federal do Rio de Janeiro, Rio de Janeiro, Rio de janeiro, Brasil.

2 Renata Oliveira da Silva, estudante doutorado engenharia metalurgia, Universidade Federal do Rio de Janeiro, Rio de Janeiro, Rio de janeiro, Brasil

3 Bruno Ekeinsten, Petrobras,

4 Dilson Silva dos Santos, professor UFRJ,Rio de Janeiro, Rio de janeiro, Brasil 


\section{INTRODUÇÃO}

Os aços Cr-Mo são utilizados para aplicação em plantas industriais energéticas, que operam em condições críticas de elevadas temperaturas e altas pressões de hidrogênio, como em equipamentos de vasos de pressão, reatores, tubulações de alta pressão, etc., sem perdas significativas de suas características mecânicas, evitando assim, que falhem catastroficamente em serviço [1,2]. Estes aços possuem elevada resistência à fluência, boa tenacidade e resistência à corrosão $[1,3]$. Sua resistência à fluência é influenciada devido aos dois tipos de mecanismos de endurecimento: por solução sólida e por precipitação, que estão relacionados diretamente com a variação de temperatura de serviço e do tempo de exposição à temperatura $[4,5,6]$. Com a adição de elementos químicos, como o $\mathrm{V}, \mathrm{Nb}$ ou $\mathrm{Ti}$, estes aços apresentam maiores níveis de resistência mecânica [1,7] e maior resistência ao ataque pelo hidrogênio, com maior temperatura de transição (dúctilfrágil) $-29^{\circ} \mathrm{C}$, melhores propriedades de fluência, menor susceptibilidade a fragilização por revenido e muito menor susceptibilidade ao descolamento, quando comparado com o aço Cr-Mo convencional [3].

Quando os aços Cr-Mo são expostos a ambientes ricos em hidrogênio, a interação hidrogênio - metal/liga pode causar uma diminuição da ductilidade e da tensão de fratura [8-9], ocorrendo mudança no aspecto da fratura (dúctil para frágil), caracterizando um fenômeno de fragilização por hidrogênio [3,10]. Nos aços Cr-Mo modificados com V, os carbetos finos do tipo MC (ricos em V) precipitam de forma dispersa, favorecendo o aprisionamento do hidrogênio difusível no aço [11]. Além disso, a adição de $\mathrm{V}$ restringe a precipitação de carbetos contendo Mo, durante o tratamento de revenido, deixando-o na matriz e retardando segregação das impurezas ao redor dos contornos de grãos, aumentando, assim, a resistência à fragilização por hidrogênio [12]. Como resultado, os aços $\mathrm{Cr}$-Mo modificados pelo $\mathrm{V}$ possuem um menor coeficiente de difusão de hidrogênio que o aço Cr-Mo convencional e isso favorece a resistência à fragilização pelo hidrogênio porque sua concentração será menor no aço. Em adição a composição química, uma grande variedade de parâmetros metalúrgicos pode influenciar a susceptibilidade a fragilização pelo hidrogênio: tipo, tamanho de distribuição de partículas de segundas fases, o tamanho de grão do aço $[4,13]$. Quando o material está submetido a uma tensão elástica aplicada, o efeito nas propriedades mecânicas é mais acentuado, em decorrência da geração de discordâncias ou distorção da rede na interface matriz/precipitado. Porém a difusão permanece constante [14,15,16].

O objetivo deste artigo é avaliar a influência do hidrogênio nas propriedades mecânicas do aço $2,25 \mathrm{Cr}-1 \mathrm{Mo}-0,25 \mathrm{~V}$ envelhecido artificialmente a $600^{\circ} \mathrm{C}$, para tempos de exposição de 100 horas e 600 horas e carregados com hidrogênio em condições diferentes, resultando na variação do nível de degradação das propriedades mecânicas do aço.

\section{MATERIAIS E MÉTODOS}

$\mathrm{O}$ aço 2,25Cr-1Mo-0,25V, utilizado para este estudo, foi fornecido pela empresa EXTERRAN Belleli Energy CPE, tratado termicamente a $600^{\circ} \mathrm{C}$ por 100 horas e 600 horas e resfriado ao ar. Após tratamento térmico, foram obtidos corpos de prova para ensaio de tração uniaxial, separados para cada condição de ensaio: somente 
tratado termicamente, carregado com hidrogênio e carregado sob tensão com hidrogênio. A composição química do material está descrito na tabela 1 .

\begin{tabular}{|c|c|c|c|c|c|c|c|c|c|}
\hline \multicolumn{10}{|c|}{ Composição Química } \\
\hline $\mathrm{C}$ & $\mathrm{Si}$ & $\mathrm{Mn}$ & $\mathrm{P}$ & $\mathrm{S}$ & $\mathrm{Cr}$ & $\mathrm{Ni}$ & $\mathrm{Mo}$ & $\mathrm{Al}$ & $\mathrm{Zn}$ \\
\hline 0,156 & 0,083 & 0,530 & 0,021 & 0,008 & 2,53 & 0,163 & 1,02 & 0,019 & 0,012 \\
\hline $\mathrm{Cu}$ & $\mathrm{Co}$ & $\mathrm{Ti}$ & $\mathrm{Nb}$ & $\mathrm{V}$ & $\mathrm{W}$ & $\mathrm{Ca}$ & $\mathrm{B}$ & $\mathrm{Sn}$ & $\mathrm{Zr}$ \\
\hline 0,112 & 0,013 & 0,0044 & 0,029 & 0,278 & 0,017 & 0,0009 & 0,0026 & 0,0081 & 0,0034 \\
\hline $\mathrm{Fe}$ & & & & & & & & & \\
\hline 95,0 & & & & & & & & & \\
\hline
\end{tabular}

Foi analisada a microestrutura, bem como a superfície de fratura, do aço em estudo por microscopia eletrônico de varredura (JEOL JSM 6460), para cada condição aplicada neste artigo. Para esta avaliação, as amostras foram preparadas metalograficamente e sua microestrutura foi revelada após ataque químico com nital $2 \%$ por um minuto. As amostras envelhecidas por 100 horas foram metalizadas com Au para melhorar o contraste da imagem.

Os ensaios de tração uniaxial foram realizados com a finalidade de observar o efeito produzido pelo envelhecimento e pelo hidrogênio nas propriedades mecânicas do aço.

\section{RESULTADOS E DISCUSSÃO}

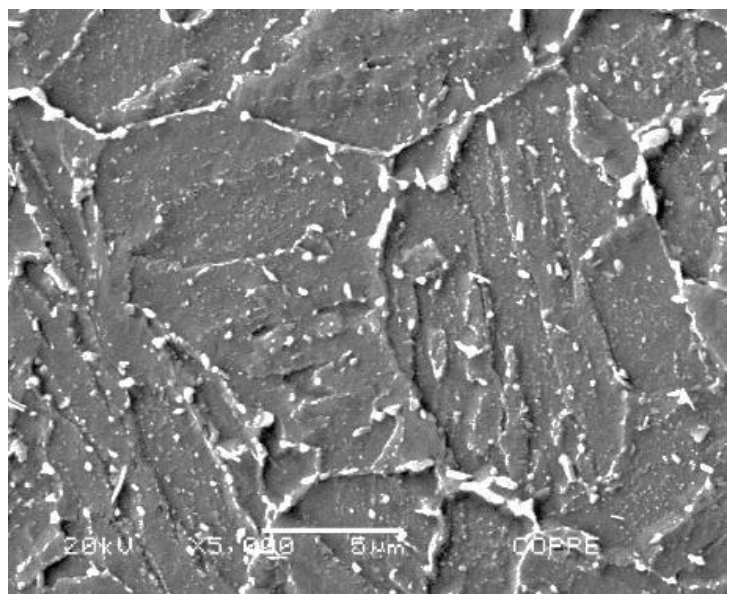

a)

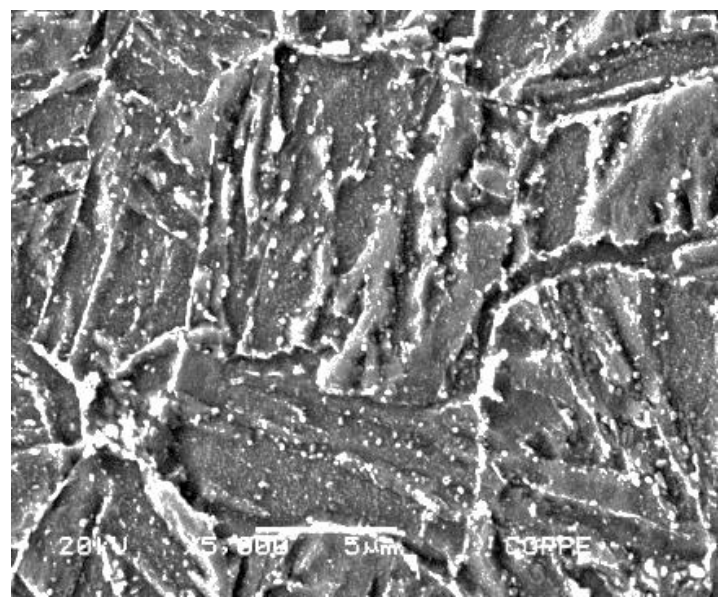

b)

Figura 1. MEV do aço $2,25 \mathrm{Cr}-1 \mathrm{Mo}-0,25 \mathrm{~V}$ no aumento $5000 \mathrm{X}$ nas condições: (a) envelhecida a $600^{\circ} \mathrm{C}$ por $100 \mathrm{~h}$, (b) envelhecida a $600^{\circ} \mathrm{C}$ por $600 \mathrm{~h}$.

A microestrutura é composta por bainita e precipitados dispersos, como observado na figura 1, com intensa precipitação no interior quanto nos contornos de grãos (figura 1a e b). Na figura $1 \mathrm{~b}$ a intensidade da precipitação e o tamanho dos precipitados foi maior para esta condição.

A figura 2 apresenta a comparação entre as curvas tensão versus deformação do aço 2,25Cr-1Mo-0,25V envelhecido a $600^{\circ} \mathrm{C}$ por 100 horas e 600 horas. 


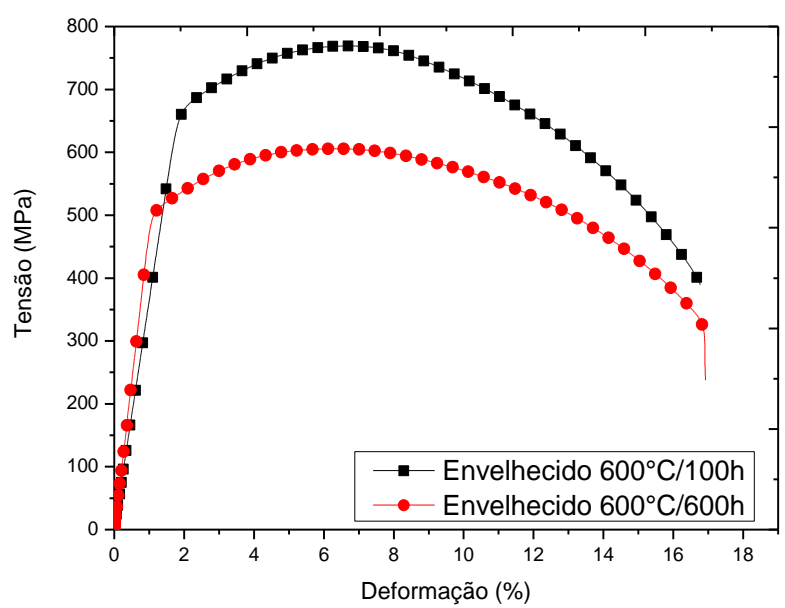

Figura 2. Curvas tensão versus deformação para o aço 2,25Cr-1Mo-0,25V envelhecido a 100 horas e 600 horas.

Para o maior tempo de exposição (600 horas), menor o limite de escoamento e a tensão máxima, no entanto, a ductilidade foi um pouco maior na observada para o aço envelhecido por 100 horas. A variação na tensão máxima para o aço nas duas condições mostrou a influência da quantidade e tamanho dos precipitados formados.

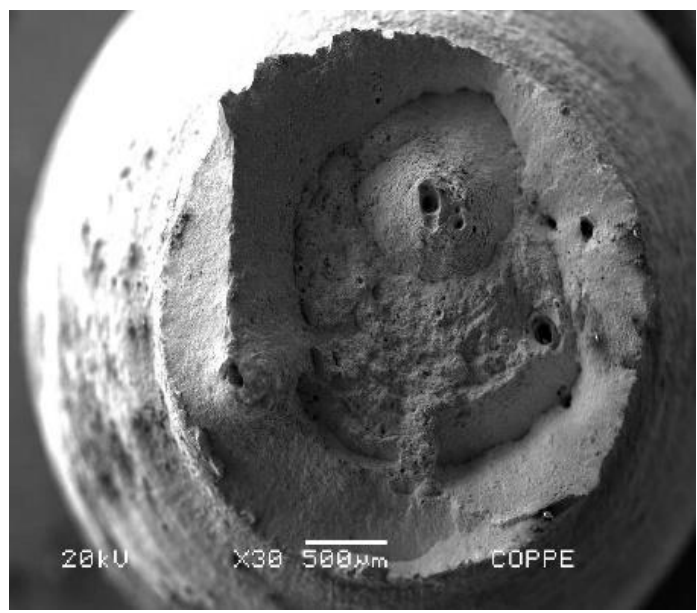

a)

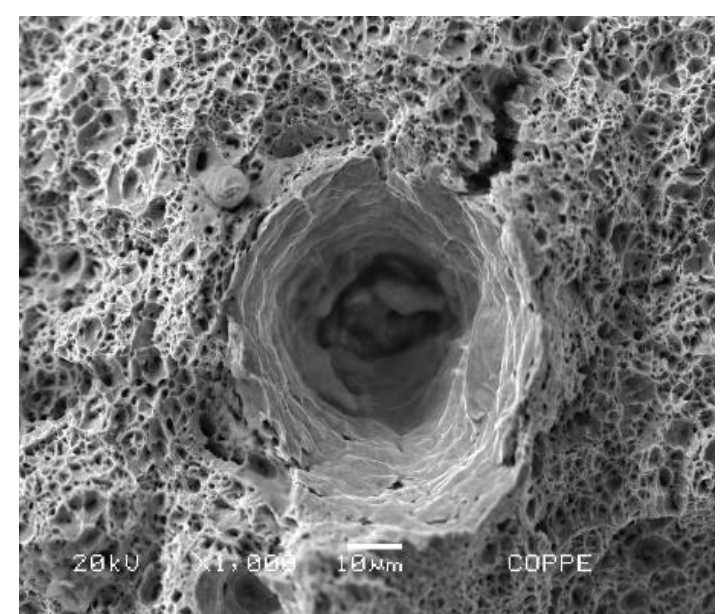

b)

Figura 3. Fractografias do aço $2,25 \mathrm{Cr}-1 \mathrm{Mo}-0,25 \mathrm{~V}$ envelhecido a $600^{\circ} \mathrm{C}$ por 600 horas. (a) Superfície de fratura. (b) formação de dimples.

Na figura 3 é observado a fratura característica de um material dúctil, taça-cone, e a presença de dimples, inclusões não metálicas e microtrincas para o aço envelhecido por 600 horas. 


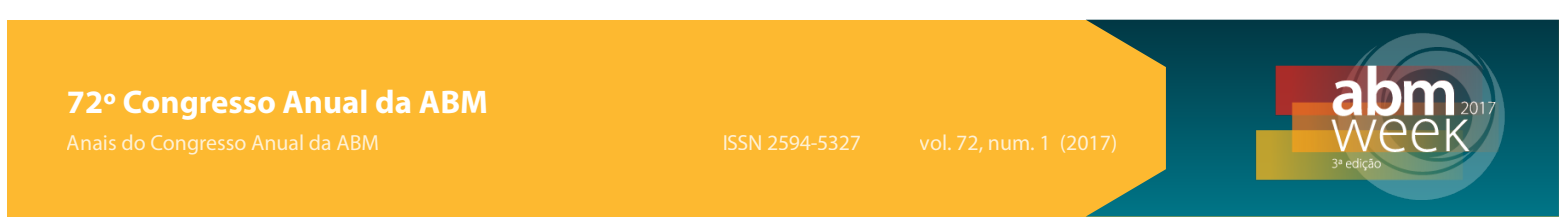

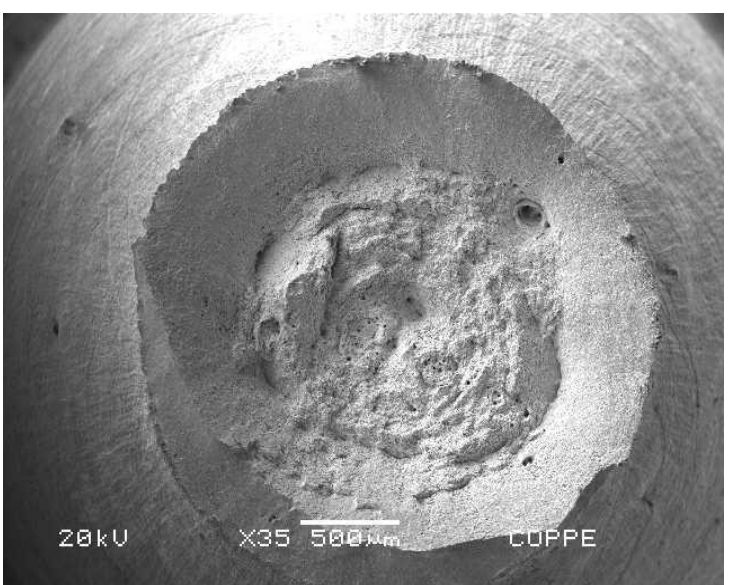

a)

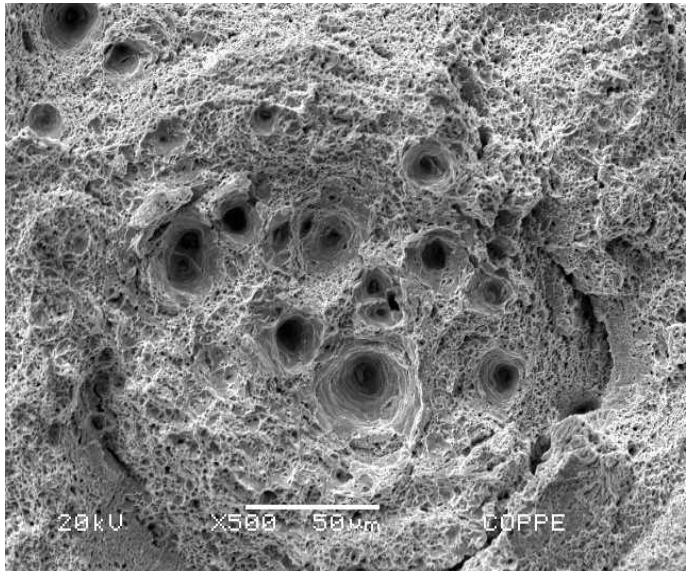

b)

Figura 4. Fractografias do aço $2,25 \mathrm{Cr}-1 \mathrm{Mo}-0,25 \mathrm{~V}$ envelhecido a $600^{\circ} \mathrm{C}$ por 100 horas. (a) Superfície de fratura. (b) Formação de dimples.

O mecanismo de fratura para os corpos de prova do aço $2,25 \mathrm{Cr}-1 \mathrm{Mo}-0,25 \mathrm{~V}$ envelhecido a $600^{\circ} \mathrm{C}$ por 100 horas também apresentou um aspecto de fratura dúctil (figura 4), com microvazios, microtrincas e dimples também foram observados.

A figura 5 apresenta a curva tensão versus deformação dos corpos de prova do aço 2,25Cr-1Mo-0,25V envelhecido e carregados com hidrogênio por 72 horas.

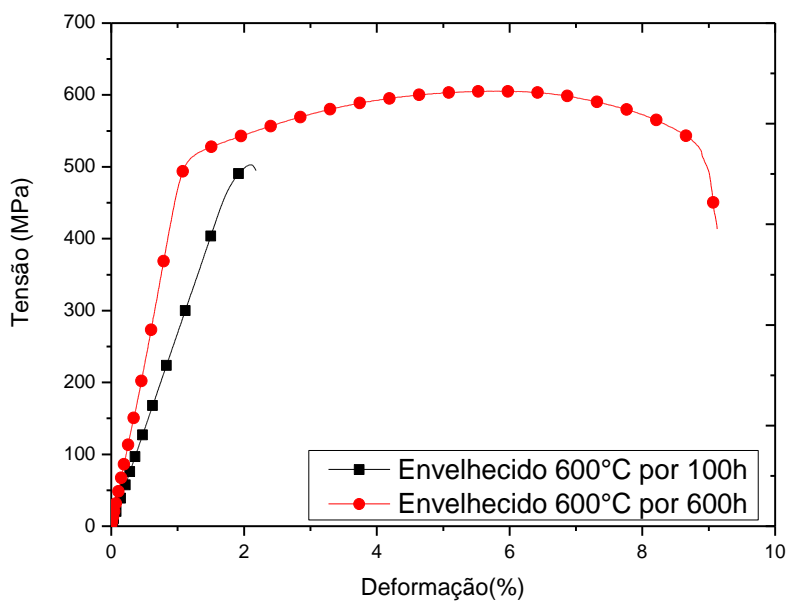

Figura 5. Curvas tensão versus deformação do aço 2,25Cr-1Mo-0,25V obtidas após envelhecimento e carregamento com hidrogênio.

Os corpos de prova envelhecidos por 100 horas apresentaram uma maior perda de ductilidade nas condições de carregado com hidrogênio por 72 horas, caracterizando a fragilização pelo hidrogênio do aço.

Os resultados por MEV das superfícies de fratura do aço em estudo são apresentados nas figuras 6 (600 horas) e 7 (100 horas). Foi observado nas duas condições uma fratura frágil do corpo de prova com a presença de zonas de quaseclivagem. 
A figura 8 apresenta a curva tensão versus deformação dos corpos de prova do aço 2,25Cr-1Mo-0,25V envelhecido e carregados sob tensão com hidrogênio por 72 horas.

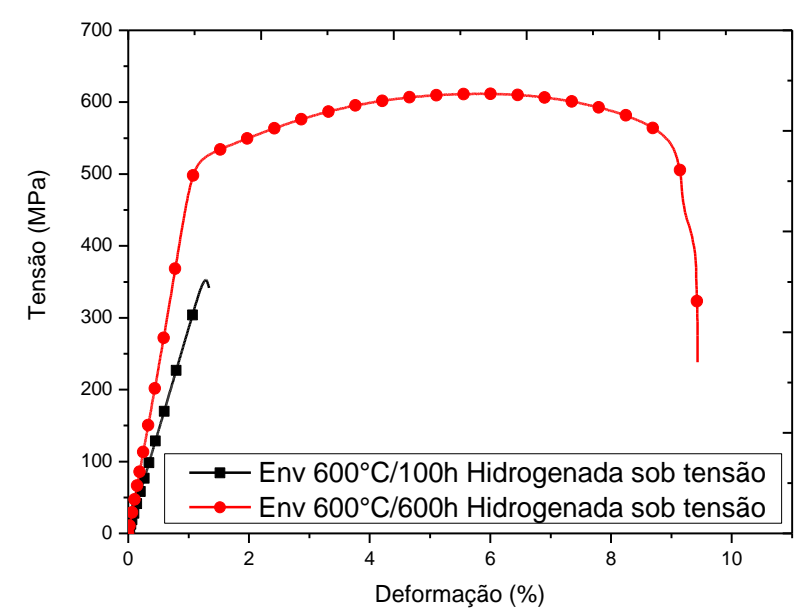

Figura 8. Curvas tensão versus deformação do aço 2,25Cr-1Mo-0,25V após envelhecimento e carregado, sob tensão, com hidrogênio.

O corpo de prova envelhecido por 600 horas e carregado sob tensão com hidrogênio não apresentou fragilização como verificado no corpo de prova envelhecido por 100 horas. As imagens da superfície de fratura são apresentadas nas figuras 9 e 10.

Este comportamento pode ter acontecido em decorrência do tamanho e dispersão da precipitação. Hadam e Zakroczymski [14] afirmaram que a degradação dos metais pelo hidrogênio depende de muitos fatores como a fonte de hidrogênio e do material em si, além da concentração e distribuição de hidrogênio no material. A aplicação de tensão elástica influencia na magnitude da taxa de permeação e na concentração de hidrogênio na rede cristalina [19]. Quando o metal é submetido a uma tensão elástica, poderá acomodar mais hidrogênio intersticial devido expansão da rede cristalina, porém o coeficiente de difusão aparente permanece constante no regime elástico, pois o hidrogênio será aprisionado no metal ao redor de precipitados coerentes ou semi-coerentes, que são sítios aprisionadores reversíveis [19]. Assim, pode-se explicar que nas amostras envelhecidas por 100 horas, o efeito foi mais acentuado devido os precipitados estarem mais dispersos, mais finos e maior quantidade de área superficial atuando como possíveis sítios aprisionadores.

O hidrogênio, devido a sua mobilidade à temperatura ambiente, alcança mais rapidamente regiões de fraca coesão como contornos de grãos e de interfaces. À medida que o hidrogênio segrega nestas regiões, principalmente àquelas entre precipitados e matriz, há uma forte diminuição dessa energia superficial levando a liga a sofrer fragilização [20]. Ainda, conforme discutido por Kirchheim [20], o hidrogênio pode se acumular ao redor dos precipitados e/ou inclusões (tipo óxidos de $\mathrm{Al}$ ) promovendo uma região de decoesão com a matriz. As figuras 11 e 12 apresentam a presença desses tipos de inclusão no aço em estudo. 


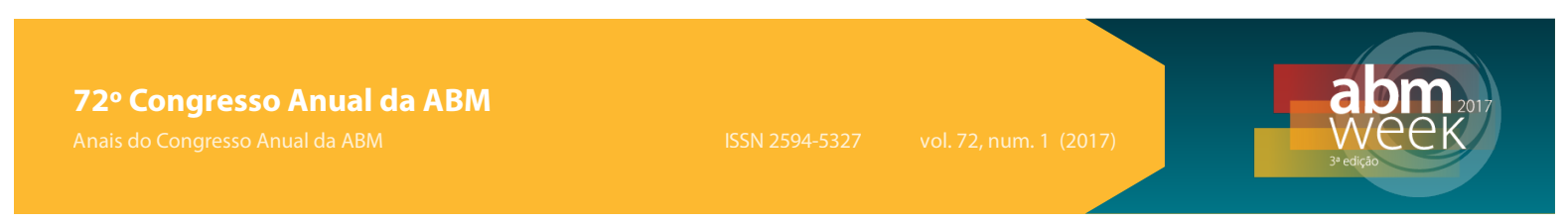

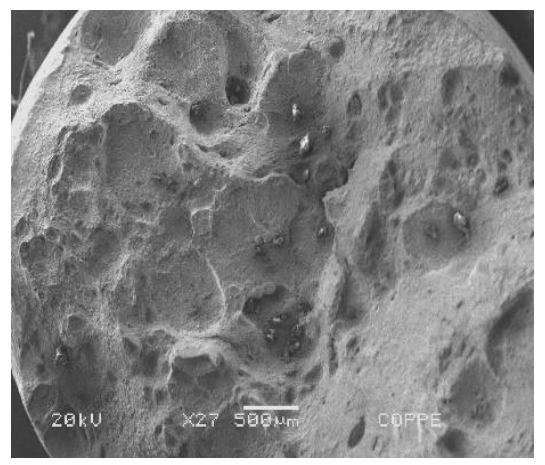

a)

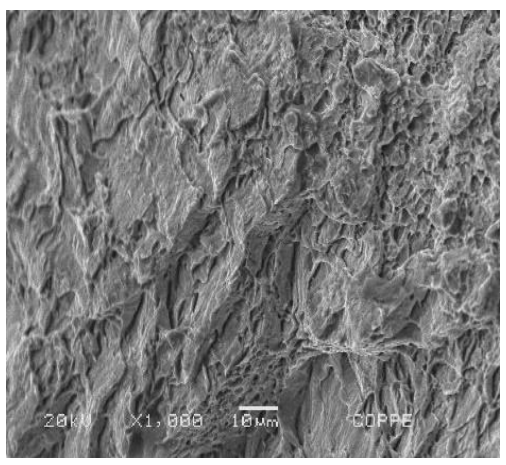

b)

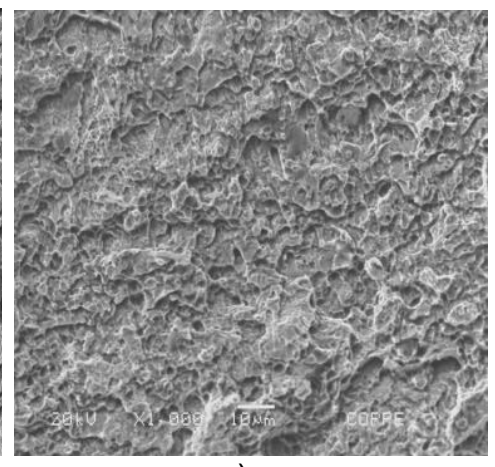

c)

Figura 9. Fractografias do aço 2,25Cr-1Mo-0,25V envelhecido a $600^{\circ} \mathrm{C}$ por 600 horas e carregado sob tensão com hidrogênio. (a) Superfície de fratura do aço, (b) Região mista de quase clivagem. c)

Região de pequenos dimples.

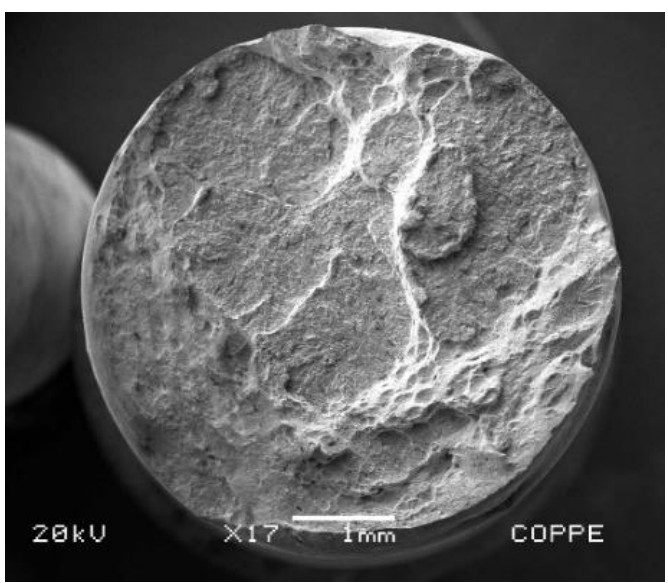

a)

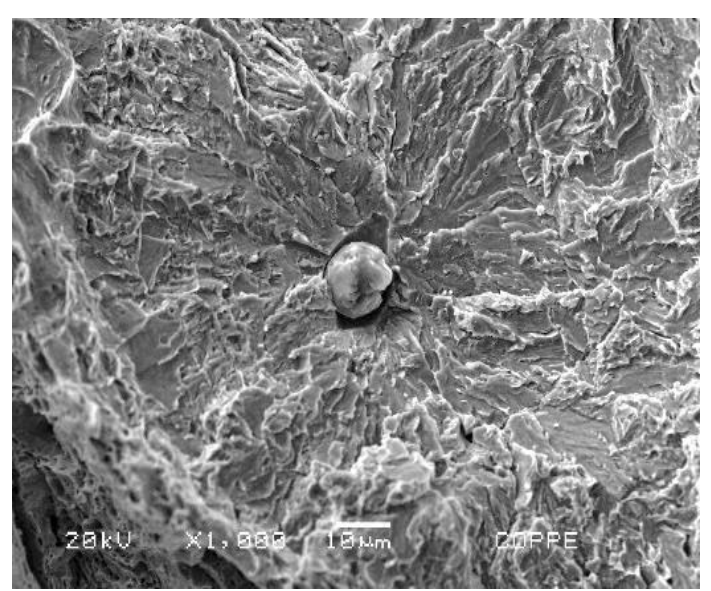

b)

Figura 10. Fractografias do aço $2,25 \mathrm{Cr}-1 \mathrm{Mo}-0,25 \mathrm{~V}$ envelhecido a $600^{\circ} \mathrm{C}$ por 100 horas e carregado sob tensão com hidrogênio. (a) superfície de fratura do aço e (b) presença de inclusão e região de decoesão ao redor da inclusão (fish-eyes).

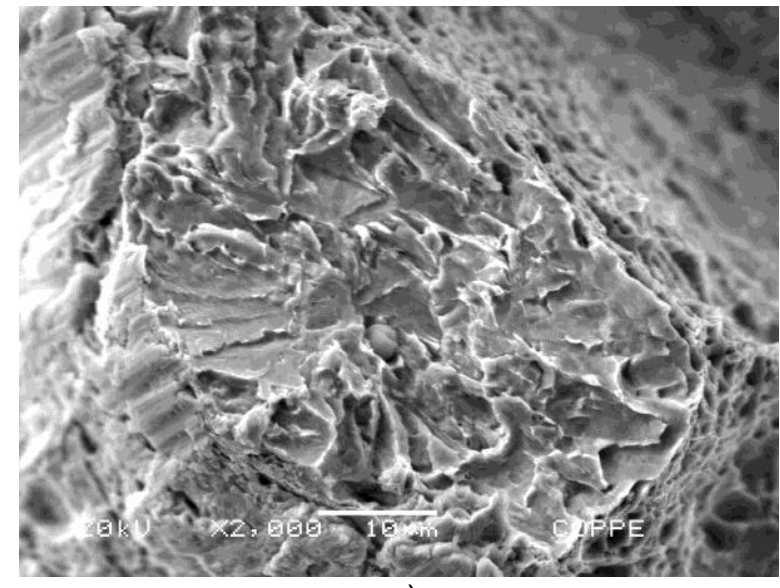

a)

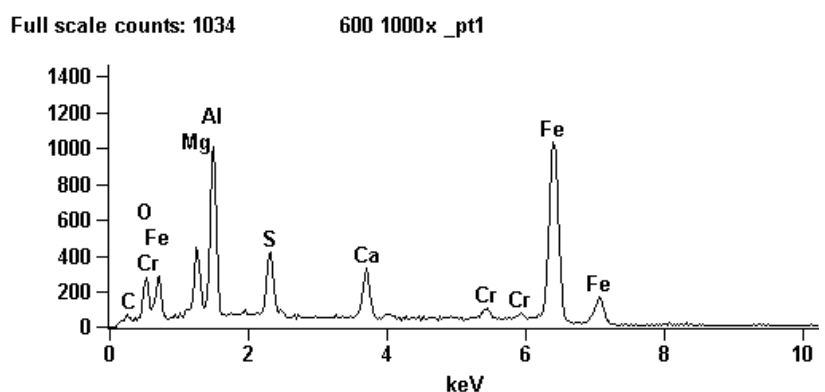

b)

Figura 11. Presença de inclusões no aço envelhecido a $600^{\circ} \mathrm{C}$ por 100 horas. Presença de inclusões. (a) inclusão formando ao redor o efeito fish-eyes e (b) EDS da inclusão. 


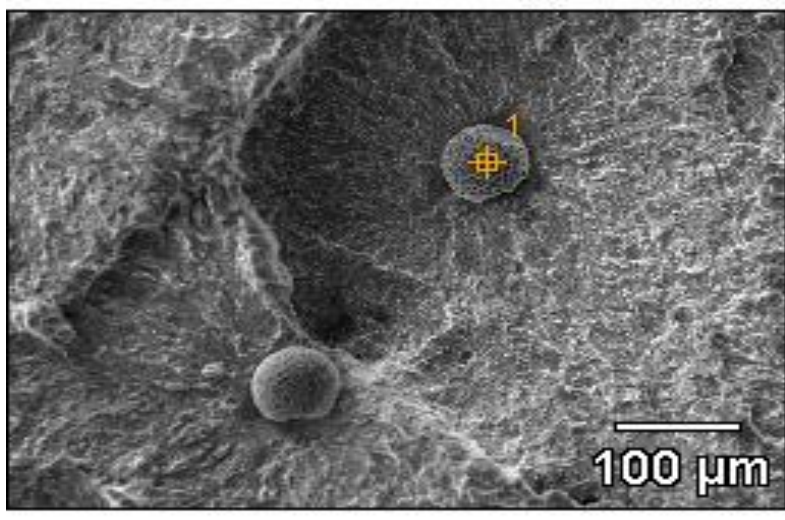

a)

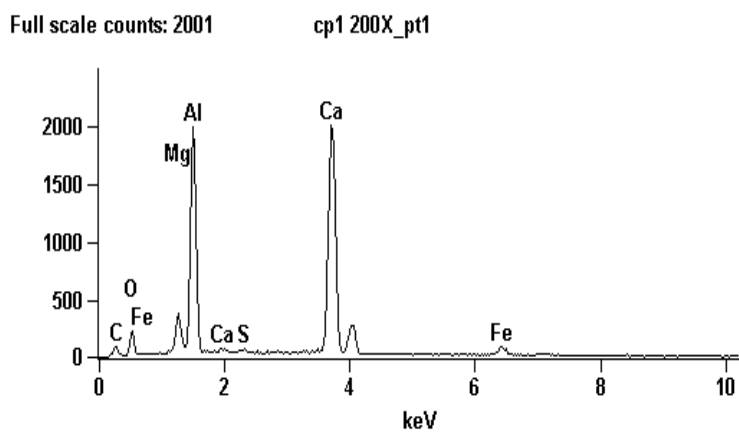

b)

Figura 12. Presença de inclusões no aço envelhecido a $600^{\circ} \mathrm{C}$ por 600 horas. Presença de inclusões. (a) inclusão formando ao redor o efeito fish-eyes e (b) EDS da inclusão

Observou-se que o hidrogênio conduziu à perda de ductilidade em todos os corpos de prova do aço 2,25Cr-1Mo-0,25V carregados com hidrogênio, no entanto, neste estudo dois comportamentos diferentes: o primeiro foi observado nos corpos de prova envelhecidos a $600^{\circ} \mathrm{C}$ por 100 horas relacionado com a influência do tamanho e dispersão dos precipitados na microestrutura do aço, que poderiam atuar como sítios aprisionadores de hidrogênio ajudando ao bloqueio da movimentação das discordâncias e, assim, diminuindo o limite de escoamento e a tensão máxima quando carregado com hidrogênio. Para os corpos de prova na condição envelhecidos a $600^{\circ} \mathrm{C}$ por 600 horas é sugerido que o hidrogênio difusível induziu a perda da ductilidade, porem as amostras carregadas com hidrogênio apresentarem valores de tensão de escoamento e tensão máxima próximos aos valores encontrados nos ensaios dos corpos de prova sem carregamento de hidrogênio. Já na condição do carregamento com hidrogênio sob tensão, houve uma redução da ductilidade, mas não ao ponto desses corpos de prova apresentaram comportamento frágil.

\section{CONCLUSÕES}

Foram evidenciadas diferenças significativas no comportamento mecânico do material exposto a diferentes tempos de envelhecimento carregados, sem e sob tensão elástica aplicada, com hidrogênio. Os resultados indicaram que o material carregado com hidrogênio e envelhecido a $600^{\circ} \mathrm{C}$ por 600 horas apresentou perda de ductilidade passando de $16 \%$ para $9 \%$, aproximadamente, em comparação com o material não hidrogenado. Para amostras envelhecidas por $600^{\circ} \mathrm{C}$ por 100 horas e carregadas com hidrogênio a perda de ductilidade foi maior, diminuindo para $2 \%$ em comparação com as amostras somente envelhecidas. que apresentaram uma ductilidade de $17 \%$. Para as amostras carregadas com hidrogênio sob tensão, foi determinada uma perda total da ductilidade do material envelhecido a $600^{\circ} \mathrm{C}$ por $100 \mathrm{~h}$. No entanto, para o material envelhecido por $600^{\circ} \mathrm{C}$ por 600 horas o limite de escoamento, a ductilidade e a tensão máxima se mantiveram em comparação às amostras carregadas com hidrogênio. 


\section{Agradecimentos}

Os autores agradecem a CNPq e a CAPES pelo financiamento para 0 desenvolvimento da pesquisa.

\section{REFERÊNCIAS}

1 Bakic G, Sijacki-Zeravcic V, Dukic M, Maksimovic V, Rajicic B. Material Characterization of $1 \mathrm{Cr}-0,25 \mathrm{Mo}-0,25 \mathrm{~V}$ power plant steel after prolonged service. First Metallurgical \& Materials Engineering Congresso f South-East Europe. 2013. [acesso em 27 mar. 2017]: 387-393. Disponível em: https://www.researchgate.net/ublication/257608033.

2 Zielinski A, Dobrzanski J, Krzton H. Structural changes in low alloy cast steel Cr-Mo-V after time creep servisse. Journal of Achievements in Materials and Manufacturing Egineering. 2007;25(1): 33-36.

3 AMERICAN Petroleum Institute. Fabrication considerations for Vanadium-modified CrMo steel heavy wall pressure vessels - API TR 934 - B. 2011.

4 Pilling J, Ridley N. Tempering of 2,25Pct Cr-1 Pct Mo low Carbon Steels. Metallurgical Transactions A. 1982;13: 557-563.

5 Bandyopadhyay N, Briant CL, Hall EL. Carbide precipitation, grain boundary segregation, and temper embrittlement in NiCrMoV rotor steels. Metallurgical Transactions A. 1985;16: 721-737.

6 Kroupa A, Vyrostkova A, Svoboda M, Janovec J. Carbide reactions and phase equilibria in low alloys Cr-Mo-V steels tempered at 773-993K. Part II: Theoretical calculations. Acta Metallurgica Inc. 1997;46(1): 39-49.

7 Djebaili $\mathrm{H}$, Zedira $\mathrm{H}$, Boumaza $\mathrm{A}$. Characterization of precipitates in a $7,9 \mathrm{Cr}-1,65 \mathrm{Mo}-$ 1,25Si-1,2V steel during tempering. Materials Characterization. 2009;60: 946-952.

8 Parvathavarthini N, Saroja S, Dayal RK, Khatak HS. Journal of Nuclear Materials. 2001;288: 187-196.

9 Lemus LF, Rodrigues JH, Santos DS, Almeida LH. Hydrogen trapping in the microstructure Cr-Mo type steels. Defect and Diffusion Forum 2009;283-286: 370-375.

10 Tan J, Chao YJ. Effect of service exposure on the mechanical properties of $2.25 \mathrm{Cr}-1 \mathrm{Mo}$ pressure vessel steel in a hot-wall hydrofining reactor. Materials Science and Engineering: A. 2005;405(1-2): 214-220

11 Torres, LFL. 2011. Influência de microestrutura com a interação do hidrogênio com o aço 2.25Cr-1Mo envelhecido. Tese de D.Sc., COPPE/UFRJ, Rio de Janeiro, RJ, Brasil.

12 Tvrdý M, Havel S, Hyspecka L. et al. Hydrogen embrittlement of CrMo and CrMoV pressure vessel steels. Int. J. Pres. Ves. \& Piping. 1981;9(5): 355-365.

13 Dunlop GL, Honeycombe RWK. Ferrite morphologies and carbides precipitation in a $\mathrm{Cr}$ Mo-V creep-resisting steel. Metal Science. 1976: 124-132.

14 Hadam U, Zakroczymski T. Absorption of hydrogen in tensile strained iron and highcarbon steel studied by electrochemical permeation and desorption techniques. International Journal of Hydrogen Energy. 2009;34: 2449-2459.

15 Brass AM, Chêne J. Influence of tensile straining on the permeation of hydrogen in low alloy Cr-Mo steels. Corrosion Science. 2006;48: 481-497.

16 Hwang LC, Perneg TP. Hydrogen transport in ferritic stainless steel under elastic stress. Materials Chemistry and Physics. 1994;36: 231-235.

17 Janovec J, Svoboda M, Blach J. Evolution of secondary phases during quenching and tempering 12\% Cr steel. Materials Science and Engineering. 1998;A249: 184-189.

18 Carter TJ, Cornish LA. Hydrogen in metals. Engineering Failure Analysis. 2001;8: 113121

19 Frappart S, Feaugas X, Creus J, Thebault F, Delattre L, Marchebois H. Hydrogen solubility, diffisivity and trapping in a tempered $\mathrm{Fe}-\mathrm{C}-\mathrm{Cr}$ martensitic steel under various mechanical stress states. Materials Science and Engineering A. 2012;534: 384-393 
20 Kirchheim, R, Somerday, B, Sofronis, B. Chemomechanical effects on the separation of interfaces occurring during fracture with emphasis on the hydrogen-iron and hydrogennickel system. Acta Materialia. 2015;99: 87-98 